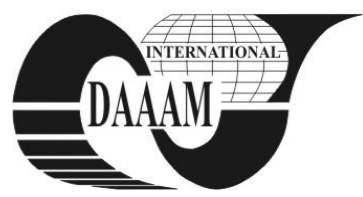

\title{
MEASURING STUDENTS' SATISFACTION AND ITS IMPORTANCE FOR IMPROVING MARKETING MIX OF SERVICES IN HIGHER EDUCATION
}

\author{
BUDIC, H[rvoje] \& ANDRLIC, B[erislav]
}

\begin{abstract}
Customer satisfaction is one of the key concept of market research. It is the best predictor of future business through indicators of loyalty and willingness of spreading positive publicity. In order to increase higher values to customers organizations must always improve all the critical activities. This work analyses importance and application of test method in order to determine students' satisfaction with the quality of educational services. Primary datas were collected using a test method. Also the area of marketing in higher education is approached and its basic determinants. Afterwards, methodology and results were presented. In the conclusion, the basic thoughts about the paper are revealed, and tactics and strategies are proposed to improve the overall level of higher education.
\end{abstract}

Key words: market research, marketing mix, customer satisfaction, survey, education, students

\section{MANAGING CUSTOMER SATISFACTION}

Customers are the greatest value of the company and they shouldn't be considered only as a objective of strategic marketing activities, but as a marketing element and a guideline of marketing management, or a part of marketing mix (Andrlic, 2010). Customer satisfaction is actually seen as a consequence of received product or service value in relation to the expected value, it is a positive or negative feeling about the value which client received as a result of using a good. In order to achieve optimum customer satisfaction, companies must provide total product that includes service and support. The aim is to vivify the concept of marketing above the traditional levels of manufacturers, wholesalers, retailers and consumers in marketing channels (Svensson, 2005). Retailers who have a higher level of customer participation, greater level of innovations and orientation towards creation of brand will probably have greater advantage in creation of brand. On the other hand, they will have more loyal customers and superior financial performance of the brand (Huang \& Huddleston, 2009). The key of the successful products is in their adaptability to changes in customers attitudes and habits. In order to successfully adjust to market changes company need to establish and accept the ways of customer's products or services valuing. Certain products or services have different values, and all of those values in combination make cognitive value and set customer's expectations. Cognitive value shouldn't be isolated, it must be supported by all the elements of the marketing mix and modern marketing which contains all the elements of traditional marketing, in which people devise, monitor and manage the process in order of achieving continuous progress in all activities (Budic, 2010). In this paper authors want to describe student customer satisfaction in education sector using marketing methods.

\section{SERVICE QUALITY}

Today, quality isn't assumed only as a technical quality, but must have some other features. It is a dynamic category, it confirms at the market and the optimum measurement instruments are customers.

There are some basic assumptions of the quality process improving; quality must be experienced by clients; quality must be included in all activities of the company; quality requires commitment of all employees; quality requires high quality partners; quality is essential, but not necessarily enough. Main difference beetwen service and product is in intangibility of the service. Therefore, quality isn't influenced by a technical features, like in product case, but the customers are the one who determine quality. Unlike TQM, which has found its origins primarily in companies that have marketed products, a concept called SERVQUAL (Service Quality) is developed, because of the specificity of services. This model provides a conceptual framework for examining the quality of services. It is based on definition of quality, as a comparison of expected and resulting, and on consideration of gaps in the process of services provision. Based on many years of using SERVQUAL model, many researchers drew many lessons from the services' quality study, and the most important are: need to constantly listen to the customers; reliability has the greatest impact on satisfaction; it is necessary to impress a client and in that way create an impact on satisfaction and loyalty; need to be extremely honest in services provision, because the service is largely invisible; design of the service must be impeccable.

\section{TEST METHOD AND ITS PROCEDURE}

Test method implies asking questions to people from which we collect datas in written or oral form. It is the most spreaded method for collecting primary datas and its advantage is reflected in huge possibilities and versatility of implementation. Test method can be clasiffied according to several criterias. The most important are the following:

- form of communication with the respodent,

- structuring degree of questions,

- clandestinity of research goals.

Form of communication with the respondent - it implies the method in which respodent gives answers (in person, by phone and mail).

Personal test - it conducts in a direct communication between examiner and respodent. The major advantage of personal test is a direct possibility of feedback about the asked question if respodent didn't understood question enough. Also, the amount of collected datas is usually higher than other forms of communication with respodent can manage. Simultaneously, with this form of test the observing can be organized.

Telephone test - conducts by phone. The major advantage of this form of communication is relatively easy accessibility of respondents. . Also, the speed of data collection is large and the examiner can immediately enter them into the computer.

Mail testing - advantages of postal survey are reflected in rather large efficiency of the procedure, covering possibilities of widely dispersed repodents, and in promotional activities of the elements attached to the examination. 


\begin{tabular}{|c|c|c|}
\hline \multicolumn{3}{|c|}{ Program and process of the study } \\
\hline The First & The Second & The Third \\
\hline 3.57 & 3.56 & 3.53 \\
\hline \multicolumn{3}{|c|}{ Teaching staff } \\
\hline The First & The Second & The Third \\
\hline 3.86 & 3.78 & 4.02 \\
\hline \multicolumn{3}{|c|}{ Non-teaching staff } \\
\hline The First & The Second & The Third \\
\hline 3.63 & 3.22 & 3.36 \\
\hline \multicolumn{3}{|c|}{ Infrastructure } \\
\hline The First & The Second & The Third \\
\hline 3.68 & 3.50 & 3.43 \\
\hline \multicolumn{3}{|c|}{ Average mark } \\
\hline 3.69 & 3.52 & 3.59 \\
\hline
\end{tabular}

Table 1. Elements of educational process

Structuring degree of questions - structured question is a question which gives the respodent possibility to give response by limited number of answers. There are three main types of

Table 1. Students' satisfaction on Polytechnic School of

Pozega according to the enrolled year of study question relating to structuring degree: dichotomous question, dichotomous question with only two answers, multiple - choice and open questions.

Clandestinity of research goals - we distinguish questions with concealed targets from those with undisguised targets (direct question in which we assume that the respondent is willing to give an answer). Question with concealed (hidden) target is indirect question which assumes the necessity of covering objectives of the study from the respondents.

\section{MARKETING IN EDUCATION}

Facing a downfall in the enrollment of new participants, facing increased costs of functioning, many private colleges use marketing to attract students and funds. Now they define better their target markets, wherewith improving communication and promotion and appropriately meeting the needs and desires of students. Marketing in education has appropriate characteristics that result from the following:

- product must be looked as a total product (it is in the form of intellectual service),

- cost of product/service is mostly paid indirectly,

- word of mouth is the best way of promotion,

- determination for consumption a product/service is influenced by rational rather than emotional motives,

The process of marketing on the higher education institutions begins with the research. Research should be conducted in accordance with society and economy needs for appropriate knowledges, and in accordance with the newest scientific achievements in the country and abroad and its transfer into the teaching plans and programs.

Marketing mix for services of higher education includes the following elements (Raybould\&Sheedy, 2005):

- product/service (subjects, directions, additional services),

- price (registration fee, school fee, other costs),

- promotion (publicity, public relations, advertising, personal selling),

- place/distribution (location of space, layout),

- people (contactibility),

- process (logistics of services delivery).

\section{METHODOLOGY, HYPOTHESIS AND} RESULTS

This testing was focused on researching students' satisfaction with the quality of educational services on Polytechnic School of Pozega, Croatia (at 2 study departments, 4 study directions, and all 3 enrolled years of study; on each enrolled year, on all three directions and two study departments, 15 students were taken in examination). The research was conducted in order to accept, or reject assumed hypothesis (H: The level of students' satisfaction with the quality of educational service on Polytechnic School of Pozega ascend in relation to the enrolled year of study).

To test the satisfaction we set up a group of specific questions related to the 4 main elements of educational process (program and process of study, teaching staff, non-teaching statff, infrastructure), as well as other general questions. For this purpose, structured questionnaire was conducted. According to the form of communication with respodents, personal test was conducted on a sample of 180 respodents, in a direct contact between respodents and examiner, and all of its advantages are used. In Table 1, we can see that the overall students' satisfaction with the quality of educational services on Polytechnic School of Pozega is highest on first enrolled study year, and it is 3.69. It falls on the second enrolled year of study, and than again, on third, it grows, and it is 3.59. However, looking at each individual element of the educational process we come to the conclusion that marks are not equal for each element individually, on all three enrolled study years, so it is in the case of program and the process of the study. The level of satisfaction with the program and the process of the study is highest on the first enrolled year, and it is 3.57, (located in category between 3 and 4; neither satisfied nor dissatisfied and satisfied). On the higher enrolled years satisfaction slightly falls, but not dramatically, almost insignificant.

\section{CONCLUSION}

Today, customer satisfaction is one of the key concepts of marketing and market research. Customers are the greatest value of the company and its satisfaction is considered as a fundamental guarantee for success and survival of the company in the long term run. In order to achieve its marketing objectives the higher education institutions should continuously conduct tactical and strategic marketing planning. Linked to Polytechnic School of Pozega we did the satisfaction survey with the quality of educational service. According to the assumed hypothesis we can say that the overall satisfaction with the quality of educational services is good. Most of the grades are located in the category from 3.50 to 4.00 , so basicly we can say that satisfaction is very good. Elements which can significantly improve marketing practice in education, in the long term, selection and modifiction of theoretical approaches in the field of social and service marketing in conjunction with educational contents, better understanding of exchange process and setting up the relationship between the marketing process, structure and functioning of education. This area is related with authors further researches in field of marketing in education.

\section{REFERENCES}

Andrlic, B. (2010). Satisfaction survey in the function of maintaining collaboration with clients. Proceedings of the 16th International Conference Maintenance: Croatian Society of maintainers, EFNMS, HIS, DAAAM International Vienna

Budic, H. (2010). Reseaching students' satisfaction with the quality of educational services. Zagreb: Faculty of Economics Zagreb

Huang, Y. \& Huddleston, P. (2009). Retailer premium own brands: creating customer loyalty through own - brand products advantage. International Journal of Retail \& Distribution Management, 37, 975-992

Svensson, G. (2005). The spherical marketing concept: A revitalization of the marketing concept. European Journal of Marketing, 39, 5-15

Raybould J. \& Sheedy, V. (2005). Are graduates equipped with the right skills in the employability stakes?. Industrial and Commercial Training, 37, 259-263 